\title{
LITERATURE REVIEW ON DEVELOPING INDUSTRY IN ETHNIC MINORITY AND MOUTAINOUS AREAS
}

\author{
Khuyen Pham Thi Minh ${ }^{*}{ }^{\circledR}$, Thuy Ha Thi Thu ${ }^{2}$, Yen Pham Thi Mai ${ }^{1}$ \\ ${ }^{* 1,2}$ Thainguyen University of Technology - Thainguyen University, Vietnam
}

DOI: https://doi.org/10.29121/granthaalayah.v8.i5.2020.172

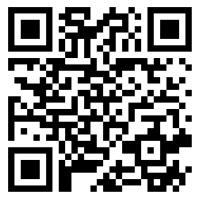

Article Type: Research Article

Article Citation: Khuyen Pham Thi Minh, Thuy Ha Thi Thu, and Yen Pham Thi Mai. (2020). LITERATURE REVIEW ON DEVELOPING INDUSTRY IN ETHNIC MINORITY AND MOUTAINOUS AREAS. International Journal of Research GRANTHAALAYAH, 8(5), 329-338. https://doi.org/10.29121/granthaa layah.v8.i5.2020.172

Received Date: 16 May 2020

Accepted Date: 31 May 2020

Keywords:

Developing Industry Industrial Development Mountainous Areas

\begin{abstract}
Ethnic minorities and mountainous areas, especially in developing countries, are often less developed than other regions. Although these areas have quite a lot of mineral resources, forest resources; harsh climates, difficult and inaccessible terrain, combined with political and social marginality certainly contribute to making difficulties in developing economies in general and industry in special. The article summarizes and analyzes previous studies on sustainable development in general, sustainable industrial development in ethnic minority and mountainous areas, in particular, to clarify which contents and issues have been studies and which contents need care for further studies, then a research model was proposed in line with the orientation of developing industry in ethnic minority and mountain areas sustainably.
\end{abstract}

\section{INTRODUCTION}

"Mountains are crucial for a global green economy. Providing 60-80\% of the world's freshwater resources for domestic, agricultural, and industrial consumption, mountains are a critical driver of food security and clean energy. Mountains also supply important minerals and genetic resources for major food crops; indeed, mountain farming is inherently green thanks to its small-scale character and low carbon footprint. Home to 17 of the 34 recognized global biodiversity hotspots, mountains play a pivotal role in conserving and harnessing biological diversity for a green economy" (Kohler T. et al. ,2012).

Because of many reasons such as: harsh climates, difficult and inaccessible terrain, underdeveloped infrastructure, especially transportation system; lack of financial resources,... industrial development strategy seems to be less concerned than general socio-economic strategies, agricultural development strategies, tourism development, ethnic culture conservation and development strategies, and poverty reduction strategies, infrastructure construction in ethnic minority and mountainous areas.

Meanwhile, with a lot of potential natural resources to develop industries such as minerals, industrial crops, hydropower, wood... massive development of industries has caused serious impacts on the natural environment and life of people in mountainous areas (most of which are ethnic minority groups in countries).

(C) 2020 The Author(s). This is an open access article distributed under the terms of the Creative Commons Attribution License, which permits unrestricted use, distribution, and reproduction in any medium, provided the original author and source are credited. 
Literature Review on Developing Industry in Ethnic Minority and Moutainous Areas

To select suitable industries that are appropriate to local potential, prepare resources to effectively exploit potentials, attract investment in green industrial production lines, and minimize environmental impacts and people's lives, local governments of ethnic minority and mountainous areas need long-term industrial development strategies, with strict management mechanisms.

This article aims to summarize and analyze previous studies on mountainous development in general, industrial development in ethnic minority and mountainous areas in particular to clarify the researched contents and issues that need clarification for further studies in line with the orientation of developing industry in ethnic minority and mountain areas sustainably.

\section{MATERIALS AND METHODS}

Desk research referring to secondary data is used to synthesize, analyze, compare and evaluate contents and experiences of developing industry in ethnic minority and mountainous areas.

Secondary data is collected from many resources: 1 . Reports of national and international organization, government on related problems in developing industry in ethnic minority and mountainous areas; 2 . Results of project related problems in developing industry in ethnic minority and mountainous areas; 3. Previous theoretical and empirical researches, articles in developing industry in ethnic minority and mountainous areas.

\section{RESULTS AND DISCUSSIONS}

\subsection{LITERATURE REVIEW ON DEVELOPING INDUSTRY SUSTAINABLY}

\subsubsection{SUSTAINABLE DEVELOPMENT}

Sustainable development, nowadays, has become a ubiquitous development paradigm: the catchphrase for international aid agencies, the jargon of development planners, the theme of conferences and academic papers, as well as the slogan of development and environmental activists (Ukaga, Maser, \& Reichenbach, 2011).

As the first official mention, in the report of World Commission on Environment and Development (WCED), also called Brundtland Report entitled "Our Common Future", in 1987, sustainable development was defined as a development that meets the needs of the current generation without compromising the ability of future generations to meets their own needs.

In report of The United Nations Conference on Environment and Development (UNCED), known as the Rio Earth Summit, in 1992, sustainable development was recommended as a priority item on the agenda of the international community" and and national strategies should be care about addressing economic, social and environmental aspects of sustainable development.

There are many perspectives and models that describe the relationship between the three basic aspects of sustainable development, but the most common ones are: Three pillars model; The "three circles" model; Nested circles model.

1) Three pillars model: The three pillars model takes the three dimensions of "environmental, economic, and social resources" (WCED, 1987) and sustainable development is only achieved when all three pillars are working in unison, if one of the pillars is unbalanced the sustainable development will collapse (Figure 2). This model is criticized because of the assumption that the "pillars" are independent constructs while three basic aspects of sustainable development are having multi relationships with each other.

2) Three overlapping-circles model: The overlapping-circles model of sustainability acknowledges the intersection of economic, environmental, and social factors. Therefore, until now, this model has been used by many researchers. Wanamaker (2018), proposed a set of interrelated concepts that should form the basis of human decisions and actions in the quest for sustainable development (Figure 2). This circular pattern fully describes aspects of sustainable development, with both standards that belong to each aspect and standards present relationship between two or three aspects. 

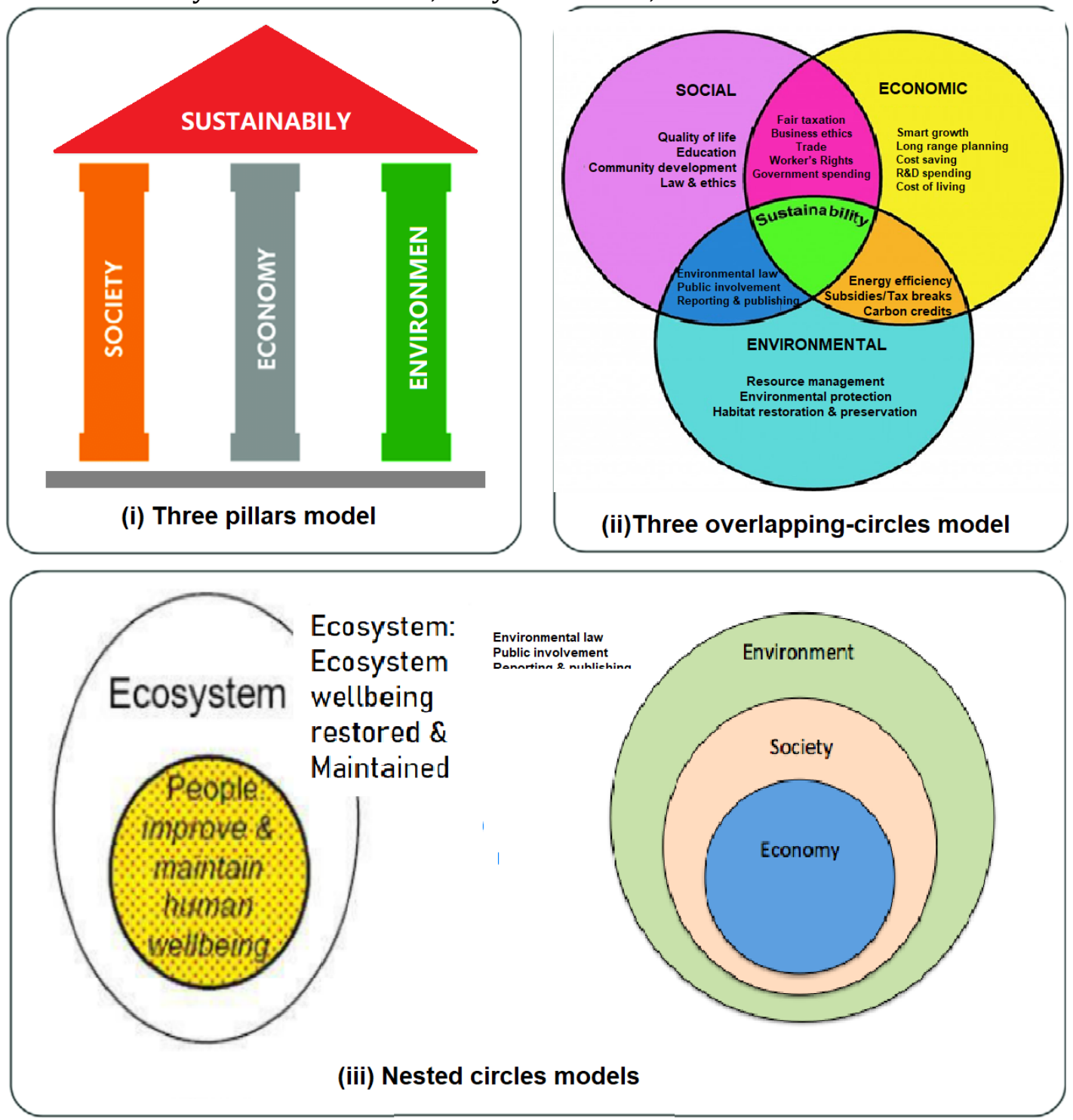

Figure 1: Relationships among social, environmental and economic sustainability.

3) Nested circles of sustainability: Nested circles of sustainability (also called the egg of wellbeing model), represents the relationships between the different dimensions as concentric ovals with one oval entirely encapsulating the other oval (Figure 2), was proposed from the IUCN (1991) definition of sustainable development and uses the metaphor of an egg, where The egg white represents the ecosystem while the yolk represents the people (Guijt et al., 2001).

The basic concentric circles model (Mitchell, 2000) is similar to the three eggs of wellbeing model except that there are more levels of subsystems; the largest circle is the natural environment which encapsulates the subsystem of human society, which in turn encapsulates the subsystem of the economy (Figure 2). It also emphasizes that each circle is constrained by the bigger one (the development of the economy is constrained by the society in which it is found which is constrained by the ecological limitations of energy and other natural resources available to the society).

\subsubsection{SUSTAINABLE INDUSTRIAL DEVELOPMENT}

Industrial development is the increase in quantity and quality of industrial growth associated with the industrial restructuring in a progressive and reasonable manner by planning and building of industries through manufacturing, provision of specialized services and commerce. Industrial development is the synthesis of contributions from four 
Literature Review on Developing Industry in Ethnic Minority and Moutainous Areas major factors, namely, Business, Technology, Government, Labor and Successful industrial projects can be achieved only through a close co-operation and mutual understanding between these contributors.

United Nations Industrial Development Organization (UNIDO) for many years has been trying to provide clearer explanations of "Sustainable Industrial Development" concept to guide solutions to all related parts in developing industries in global, national and regional levels. The first definition of "Ecologically sustainable industrial development" was proposed by UNIDO Conference on Ecologically sustainable industrial development (UNIDO,1993). "Ecologically sustainable industrial development is defined as patterns of industrialization that enhance economic and social benefits for present and future generations without impairing basic ecological processes". The conference also proposed three criteria tha a particular pattern of industrialization must satisfy if it is deemed ecologically sustainable, either absolutely or in comparison to other patterns: (i) protect the environment; (ii) contribute to the competitive development of industry; (iii)promote social equity.

The Lima Declaration, adopted by UNID0's Member States in December 2013, set the foundation for a new vision of inclusive and sustainable industrial development and especially emphasizes the importance of technology and innovation: "Inclusive and sustainable industrial development (ISID) is the primary source of income generation, allows for rapid and sustained increases in living standards for all people, and provides the technological solutions to environmentally sound industrialization".

The viewpoints of UNIDO in these definitions have been applying in many researches.

Kum-Chun Seetoh and Amanda Ong (2008) discussed the Singapore Model of achieving sustainable industrial development through a system of strategic planning and implementation: from the 1960s to 2000s. They illustrate how Singapore began with the low-cost and labour-intensive industrialization programme which systematically transformed itself to capital-intensive and high-tech and high-value-added over four decades. Industrial growth and the expanded market share have enabled JTC Corporation to pay greater attention to environmental measures in order to safeguard the living environment whilst intensification of the industrial land has become inevitable.

Jan Harmsen Joseph B. Powell (2010) provided a general viewpoint about industrial sustainable development and proposed solutions to promote industrial enterprises to continue developing by facing environmental and social challenges in industrial production. From an overview of the definitions of sustainable development, the authors have confirmed the role and impact of industrial development on sustainable development. With quantitative studies of specific cases in the fields of chemicals, oil and gas, material production, and mining, the research introduces ways for enterprises to use resources effectively through cooperation between stakeholders in different industries to achieve development from the perspective of sustainable development on all three sides: economic, social, and environmental.

Quoc Cuong Nguyen \& FeiYe (2015), has proposed an indicator system with sustainable industrial development to evaluate the current status of industrial development in 13 provinces and cities of the Mekong Delta. By using a quantitative approach, and principal component analysis method, the results of the study indicated that industrial development in the Mekong Delta is unsustainable and the efficiency in developing the industrial sector to create the socio-economic growth and promote the Mekong Delta's environment exhibited a downward trend. After ranking the sustainability of industrial development in 13 provinces and cities of the Mekong Delta, some solutions are proposed to achieve sustainable industrial development in the Mekong Delta of Vietnam.

$\mathrm{Li}$, Huijun et. al (2018) investigated the implications of continued industrial economic growth on environmental pollution in China in order to inform strategic policies to achieve sustainable development of the industrial sector. Green total factor productivity (TFP) for each industrial sector was calculated by estimating the Global MalmquistLuenberger (GML) index using a Slacks-based Measure Directional Distance Function (SBM-DDF). The average annual rate of green TFP increased at 5.68\% over the 11-year period. A hierarchical clustering procedure to group all industrial sectors into green-intensive, intermediate and extensive clusters based on the contribution of green TFP to industrial economic growth within respective industries, and econometric estimation of the relationship between pollutant levels and industrial GDP per capita, were used to investigate the relationship between industrial economic growth and pollutant levels. The research results showed clear evidence in favor of the Environmental Kuznets Curve (EKC) theory only with wastewater as the primary pollutant of interest and only with industrial sectors that are already relatively pollution-intensive. 


\subsubsection{SELECTING AN APPROPRIATE INDUSTRIAL DEVELOPMENT MODEL AND SUITABLE SUB INDUSTRIES.}

Zhang, Y. et al. (2011), basing on the long-term researches on mountainous area development and following a brief exploration into the connotations and the spatial organizing process of valley economy in Beijing's mountainous areas, show that valley economy plays an important role in the development and functional transformation in Beijing's mountainous areas in the new epoch. Firstly, the valley economy is not outlined by the administrative boundaries, and it connects most of the villages in the mountainous areas roughly along the major transportation lines. Therefore, the valley economy can exert a positive influence on the development in the mountainous areas, at least in the aspects such as the rearrangement of industrial structure in the mountainous areas and the coordinated development of rural and urban areas. Secondly, the valley economy in Beijing's mountainous areas is evolved in a spatial organizing stage of secondary concentration, which is characterized by resource-saving, ecological protection, and industrial optimization. Therefore, the development of the valley economy will be helpful to the coordination between ecological protection and economic development in the mountainous areas and will promote the integrated development of the mountainous areas.

In 2012, the United Nations Conference on Sustainable Development (UNCSD) or Rio+ 20 was held the third time, focused on two themes in the context of sustainable development: green economy and an institutional framework. On the Rio+ 20 report, when analyzed the situation of green economy in mountainous areas report also recommends solutions for three main green sub-industries in : (i) Government brings stakeholders together with encourage polices and strict management mechanisms with green and sustainable orientations and helps the mining companies fulfill their sustainability objectives in an efficient, effective, and equitable manner; (ii) Community-based forestry and selective logging practices introduced by large companies have demonstrated benefits both to conservation and economic development; (iii) Allow for hydropower scalability based on multiple partnerships, including the private sector. Public funds are leveraged to raise community equity, in addition to funds from capital and carbon markets. The ownership of smaller hydropower is community-based, whereas larger units of $0.5 \mathrm{MW}$ and higher are designed to operate as formal power utilities, with the triple bottom-line of economic gain, social services and environmental protection.

Jingfu Guo Yingnan Dong (2012) researched on sustainable development strategies in Ethnic Chinese Areas. The author has shown a three-dimensional model of regional sustainable development: (i) Economic development; (ii) Social progress; (iii) Natural resources and environment. Then, the authors also discussed the sustainable development of the cultural advantages of ethnic minorities in China, and explored strategies for sustainable development for ethnic Chinese combined with guidance to achieve development such as sustainable development such as developing the ecological ethics of ethnic minorities, educating the awareness of ecological citizens, completing policies and regulations to protect the ecological environment of ethnic minority areas, promoting build clean industrial ecosystems, and develop non-carbon or industrial Low-carbon businesses in ethnic Chinese regions.

When mentioning to industrial development in Chinese ethnic Regions, the author recommended promoting the construction of Industrial ecosystem and clean production of "Cell Engineering". Through the simulation of natural ecosystems and the establishment of organic circular industrial development model, industrial ecology aims to solve the problems in industrial economic development, environmental protection, and sustainable uses of resources. Enterprises can make full use of resources, reduce wastes, use recycled materials, eliminate environmental damages, and improve the scale and quality of economic development, achieve sustainable economic development and harmony between man and the nature. Thus, industrial ecology is a new industrial development model, to be sure to achieve sustainable development, we should try hard to promote construction of industrial ecosystem in Chinese minority areas.

Vishwambhar Prasad Sati (2014), when mentioned the opportunities for sustainable mountain development, also emphasized that abundance in natural resources can be harnessed in a sustainable manner for the overall industrial development of the mountainous region: (i)Mountains are also rich in minerals as well as metals, including gold, copper, iron, silver and zinc. Owing to increasing demand, mines are now being opened even in remote mountain areas, particularly in the developing countries; (ii) A large variety of forest produce, medicinal plants, natural dyers and natural fibre plants are plentiful; these resources could be harnessed advantageously to produce useful and high-value items; (iii) Water resources in the form of hydroelectricity generation and water supply for 
Literature Review on Developing Industry in Ethnic Minority and Moutainous Areas drinking and irrigation purposes will surely lead to the sustainable development of the region; (iv) High biodiversity makes these areas immense opportunities for developing Agro and Food Processing Industries;

Wymann von Dach et al (2016) in a project of Austrian Development Cooperation and Swiss Agency for Development and Cooperation on "Investing in the sustainable development of mountainous areas - Opportunities, resources, and benefits", showed experiences in developing economies in mountainous areas of some countries: (i) Formalizing the artisanal and small-scale mining sector supported by an enabling legal framework; (ii) Spatial planning of investments in hydro-power requires an initial comparison of all projects in the planning phase, in terms of socioecological costs and macroeconomic benefits of potential locations and contexts; and especially resettlement of hydropower projects and cumulative impacts of hydropower on the national and river-basin levels; (iii) Cooperative forms of inclusive entrepreneurial initiatives, linking training and small-scale rural industries, are likely to trigger a more comprehensive economic development.

\subsubsection{INSTITUTIONS THAT PROMOTE SUSTAINABLE DEVELOPMENT IN ETHNIC MINORITY AND MOUNTAIN REGIONS}

Because of the importance of mountainous areas to the global economy, from local levels to global levels, many stakeholders are involved in sustainable mountain development: Government, international treaties, networks of non-governmental organizations, municipalities, and researchers, farmer cooperatives, resource user groups, and tourism operators.

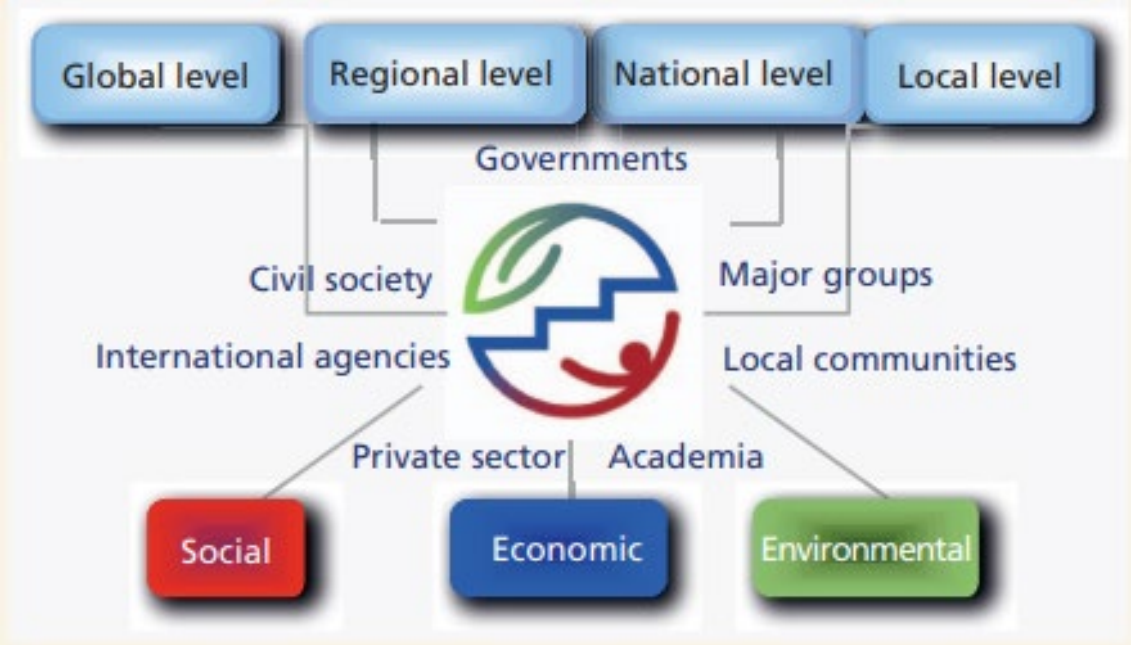

Figure 2: Institutions that promote sustainable development in mountain regions.

Source: Kohler T. et. Al (2012).

Kohler T. et. Al (2012), in report of RIO 2012, named many institutions from global level, regional level, national level, and local level and their roles in developing mountainous areas. Reports also presented that, since the early 1990s, global and transnational initiatives have greatly influenced state action in managing mountainous areas. Accordingly, institutional frameworks for sustainable development strategies in mountains and beyond are increasingly organized in complex and multilevel arrangements. However, States still are the most important institutions creating and enforcing rules and regulations for the use and the management of mountain regions. While few states have specific legal instruments or administrative units for mountains, their wide-ranging sectorial policies have tremendous impacts in mountain regions. Trade liberalization, privatization, agriculture and forest policies, energy development, cultural minority policies, tourism development, and many other specific policies have various consequences in mountain areas and for the people who live there.

\subsubsection{PROBLEMS ARISING FROM INDUSTRIAL DEVELOPMENT TO THE ENVIRONMENT AND SOCIO-CULTURE}

Besides bringing large benefits, industrial development also cause many problems to the environment and socio-culture. Clear-cutting of timber led to landslides, loss of soil, erosion, and flooding in areas as disparate as Indonesia and Alaska. Large-scale mines were - and many remain - infamous for the devastation they have caused 
Khuyen Pham Thi Minh, Thuy Ha Thi Thu, and Yen Pham Thi Mai

to local communities, ecosystems, and cultures. Even so-called "artisanal" mining caused disease and permanent damage to water sources from unregulated storage and use of heavy metals such as cyanide, arsenic, and mercury (Rio, 2012).

Vishwambhar Prasad Sati (2014), showed that mining can be devastating to fragile mountain ecosystems and local cultures, destroying the livelihood base of mountain communities. Massive quantities of waste, surface dumps and slag heaps are only the most visible consequences. Mining leads to atmospheric pollution and the loss of biodiversity and vegetative cover, which in turn destabilises mountain slopes. Water contamination is especially serious because mountains are reservoir of drinking/irrigation water.

Nodar Elizbarashvili et al. (2018), gave evidence that the construction of reservoirs for the development of hydropower in mountainous areas, on the one hand, help regulate the water resources efficiently, but on the other hand, they contribute to increasing seismic pressure, flooding the riverside terraces, forests and meadows, which are of a particular significance for the mountain dwellers, changes of the microclimate, underground water level, generic structure of the wildlife and their migration routes, etc. Otherwise, the migration of the people of the mountainous regions, irrational and rapacious use of the natural resources, degradation of cultural and ethnic values, different kinds of conflicts, and level of poverty of the mountain dwellers will intensify further.

\subsubsection{AFFECTING FACTORS TOWARD DEVELOPING INDUSTRY IN ETHNIC MINORITY AND MOUNTAINOUS AREAS}

Carrying out a large-scale diversification and modernization of economic systems through initiating industrialization and large-scale production system is severely limited in hilly and mountainous areas because of a number of factors-such as the availability situation of limited environmentally sensitive resource bases and the spread of usable resources across different and inaccessible areas. Factors such as inaccessibility to markets/modern inputs/technology, deficient infrastructure, and high transport costs are also leading to the noncompetitiveness of products (Mehta 1996).

Vishwambhar Prasad Sati (2014), proposed that the high rates of growth in developing mountainous areas affected by the administration and governance, together with fiscal incentives for private participation in these sectors.

Wymann von Dach et al (2016), showed that mountainous areas face many challenges of attracting investment: (i) High cost to bring investment resources (goods and services, specific expertise) into mountain areas, develop needed skills, and transport goods produced to markets; (ii) sparse populations maybe offer less local market potential and political support in return for public investments; (iii) Lack of investment in efforts to increase the resilience of communities and ecosystems leads to disproportionate damage from natural disasters and higher costs of climate change, and these risks, in turn, lower the potential returns on investment; (iv) Lack of policy attention and Weak management system; (v) lack of infrastructure in mountains of the developing.

Wymann von Dach et al (2016), and International Fund for Agricultural Development (IFAD, 2014) with the study "Georgia Development Program for mountainous areas and highland Georgia - Performance evaluation", are both showing the role of infrastructure investment policy to promote and attract investments flows in developing and expanding production activities of enterprises and households, to contribute to improving rural and mountainous livelihoods as well as increasing income and food security. In addition to improving connectivity among regions, public investment in infrastructure for social facilities and public services has the effect of improving the quality of life and increasing access to services for ethnic people. the mountains, thereby attracting migrants to invest to develop production and business.

Guoping Huang (2017), analyzed historical urban growth trends in this mountainous region to better understand the interaction between the spatial growth pattern and the mountainous topography. Three major factors-slope, accessibility, and land use type-were studied in light of their relationships with urban spatial growth. With the analysis of historical data as the basis, a conceptual urban spatial growth model was devised. In this model, slope, accessibility, and land use type together create resistance to urban growth, while accessibility controls the sequence of urban development. The model was tested and evaluated using historical data. It serves as a potential tool for planners to envision and assess future urban growth scenarios and their potential environmental impacts to make informed decisions. 


\section{DISCUSSION}

Literature Review on Developing Industry in Ethnic Minority and Moutainous Areas

\subsection{THE CONTENT HAS BEEN CLARIFIED}

Sustainable development of ethnic minorities and mountainous areas plays an increasingly important role in many countries, especially countries with large mountainous areas.

Previous projects and researches have clarified many issues related to the sustainable development of ethnic minorities and mountainous areas in general, industrial development of these areas in particular. Some main achievements:

Firstly, the concepts of sustainable development and sustainable industrial development are clarified and updated according to the socio-economic development in each period.

Secondly, contents of sustainable industrial development and effective factors were mentioned in both theoretical and empirical researches, projects and conferences.

Thirdly, both politicians and scientists agree that industrial development can brings large benefits but also makes disadvantages to the environment and socio-culture, thus, the development of industries in the mountainous areas must be done in the right and purposeful manner, by considering the principles of sustainable development.

Fourthly, all studies have confirmed the importance of ethnic minority communities for each country; as well as the importance of mountainous areas that provided a lot of natural resources and contained large forest areas. Therefore, industrial development in particularly, and socio-economic development in general in ethnic minority and mountainous areas, have become important issues in many management levels: local level, national level, regional level and global level.

Finally, there are many factors affecting sustainable industrial development in ethnic minority and mountainous areas, some are negative effects, some are positive effects.

\subsection{SPACE FOR FURTHER RESEARCH}

Firstly, most studies have mentioned many aspects of industrial development and highlight the situation of industrial development in some ethnic minority and mountainous areas in the world. Many policies and solutions from local to global level have been implemented to promote the development of industrial development in this area, in order to bring the mountains "up to" with the plains. However, separate studies on industrial development in ethnic minority and mountainous areas are still limited, especially those based on interdisciplinary approaches linking industrial development with socio-economic issues and natural environment of ethnic and mountainous areas.

Secondly, although politicians and scientists have made an evaluation opinion on the effectiveness and impact of industrial development policies as sustainable orientation, however, the unity among countries and scientists on the criteria system reflects the situation of industrial development in is still at a very low level;

\section{CONCLUSIONS AND RECOMMENDATIONS}

Sustainable industrial development in ethnic minority and mountainous areas is difficult and challenging, however, if implemented well, it will bring great benefits to the countries. Basing on summarizing and analyzing previous studies on industrial development in ethnic minority and mountainous areas in sustain orientation, the research model on developing industry in ethnic minority and moutainous areas has been proposed as in Figure 3. Therefore, to describe the situation of industrial development in ethnic minority and mountainous, some main contents need to be clarified:

1) National industrial system

2) Ethnic minority and mountainous areas

3) Related parties

4) Activities to develop Industry in the ethnic minority and mountainous areas

5) Evaluation criteria to measure industrial development efficiency

6) Effecting factors toward developing industry in ethnic minority and mountainous areas 


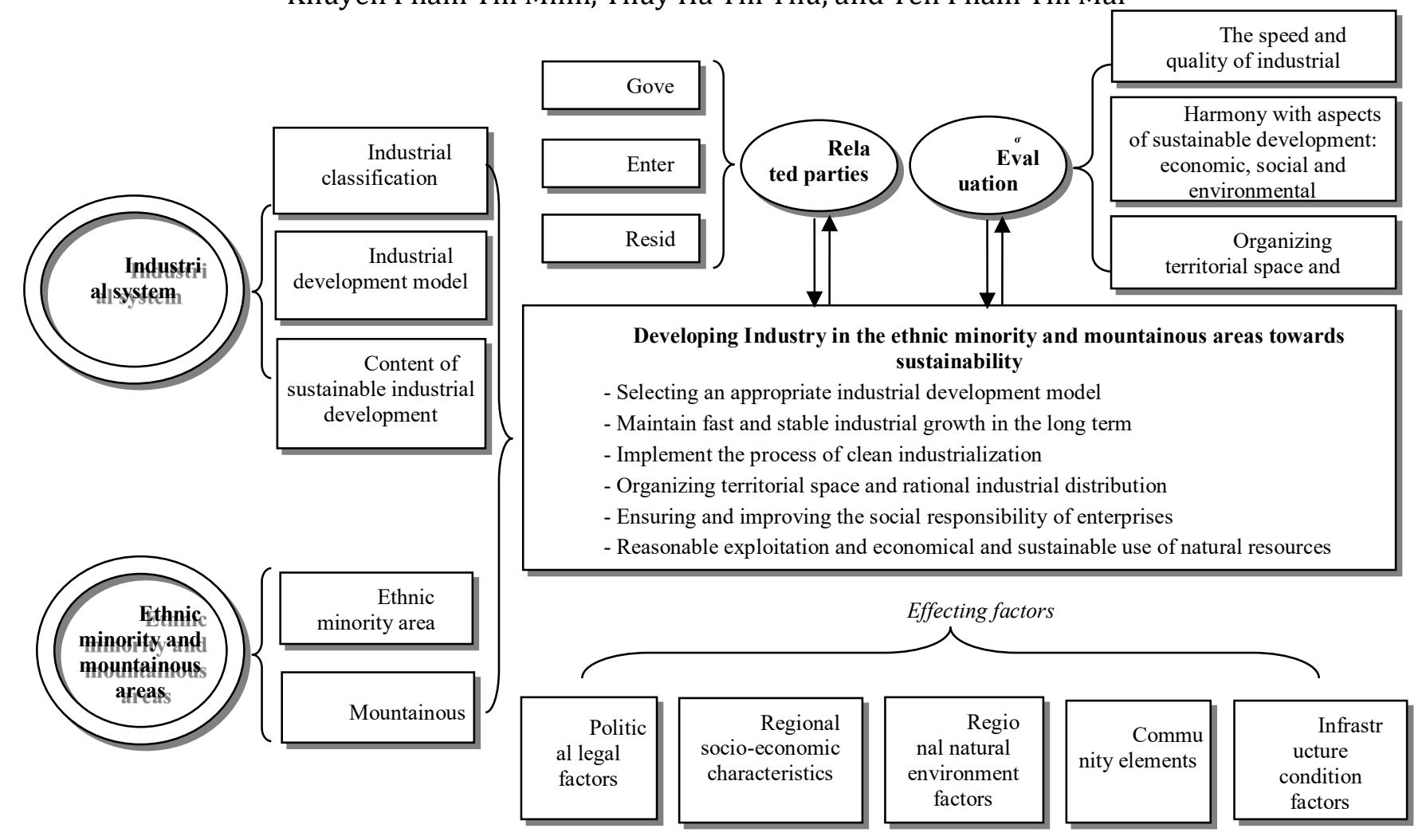

Figure 3: Research model on developing industry in ethnic minority and moutainous areas

\section{SOURCES OF FUNDING}

None.

\section{CONFLICT OF INTEREST}

None.

\section{ACKNOWLEDGMENT}

The article is a product of a state-level scientific Project, Code: CTDT 38.18/16-20, "Researching on industrial development in ethnic minority and mountainous areas of Vietnam - Situation and solutions".

\section{REFERENCES}

[1] Kohler T; Pratt J; Debarbieux B; Balsiger J; Rudaz G; Maselli D; (eds) 2012. Sustainable Mountain Development, Green Economy and Institutions. From Rio 1992 to Rio 2012 and beyond. Final Draft for Rio 2012.

[2] Ukaga, U., Maser., C., \& Reichenbach, M. (2011). Sustainable development: principles, frameworks, and case studies. International Journal of Sustainability in Higher Education, 12(2), Emerald Group Publishing Limited. doi:10.1108/ ijshe.2011.24912bae.005

[3] World Commission on Environmental Development (WCED, 1987). Our Common Future. Report of the World Commission on Environment and Development. Oxford University Press: Oxford.

[4] UNCED (1992), Report of the United Nations Conference on Environment and Development, Volume I: Resolutions Adopted by the Conference, United Nations Publication, New York.

[5] Wanamaker, C. (2018) The Environmental, Economic, and Social Components of Sustainability: The Three Spheres of Sustainability: Adapted from the U.S. Army Corps of Engineers https://soapboxie.com/socialissues/The-Environmental-Economic-and-Social-Components-of-Sustainability [Google Scholar] 
Literature Review on Developing Industry in Ethnic Minority and Moutainous Areas

[6] International Union for Conservation of Nature and Natural Resources (IUCN, 1991). Caring for the Earth. A strategy for sustainable living. Gland, Switzerland.

[7] Guijt, I., Moiseev, A. \& Prescott-Allen, R. (2001). IUCN resource kit for sustainability assessment. Part A: overview. IUCN: Gland, Switzerland.

[8] Mitchell, C. (2000). Integrating sustainability in chemical engineering practice and education: concentricity and its consequences. Transactions of the Institution for Chemical Engineering, 78(B), 237-242.

[9] United Nations Industrial Development Organization (UNIDO, 1993), Annual Report of Unido 1992

[10] United Nations Industrial Development Organization (UNIDO, 2013), Decisions and resolutions, including the Lima Declaration, of the General Conference Fifteenth regular session, Lima, 2-6 December 2013. https://www.unido.org/sites/default/files/files/2019-02/gc15_inf4e.pdf.

[11] Seetoh K.C., Ong A.H.F. (2008) Achieving Sustainable Industrial Development Through a System of Strategic Planning and Implementation: The Singapore Model. In: Wong TC., Yuen B., Goldblum C. (eds) Spatial Planning for a Sustainable Singapore. Springer, Dordrecht

[12] Jan Harmsen Joseph B. Powell (2010), Sustainable development in the process industries, John Wiley \& Sons, Inc, Hoboken, New Jersey, USA

[13] Quoc CuongNguyen, FeiYe (2015), Study and evaluation on sustainable industrial development in the Mekong Delta of Vietnam, Journal of Cleaner Production, Volume 86, 1 January 2015, Pages 389-402.

[14] Li, Huijun \& Zhang, Jianhua \& Osei, Edward \& Yu, Mark. (2018), Sustainable Development of China's Industrial Economy: An Empirical Study of the Period 2001-2011. Sustainability. 10. 764. 10.3390/su10030764.

[15] Zhang, Y., Jia, D., Zhang, H. et al. (2011), "Spatial structure of valley economic development in the mountainous areas in Beijing", Journal of Geographical Sciences, Volume 21, Issue 2, pp 331-345. https://doi.org/10.1007/s11442-011-0848-3

[16] Jingfu Guo Yingnan Dong (2012), "Research on the Strategies of Sustainable Development in Chinese Ethnic Regions", International Journal of Academic Research in Business and Social Sciences, Vol. 2, No. 6, pp.443450.

[17] Wymann von Dach, S., Bachmann, F., Borsdorf, A., Kohler, T., Jurek, M. \& Sharma, E., eds. (2016), Investing in sustainable mountain development: Opportunities, resources and benefits. Bern, Switzerland, Centre for Development and Environment (CDE), University of Bern, with Bern Open Publishing (BOP). https://www.researchgate.net/publication/

293428232_Investing_in_Sustainable_Mountain_Development_Opportunities_Resources_and_Benefits [accessed January 22 2020].

[18] Vishwambhar Prasad Sati (2014), Towards Sustainable Livelihoods and Ecosystems in Mountain Regions, Springer, Switzerland. Doi: 10.1007/978-3-319-03533-8.

[19] Nodar Elizbarashvili, Heino Meessen, Ashot khoetsyan, Giorgi Meladze, Thomas Kohler (2018). Sustainable development of Mountain Regions and Resource Management. Textbook. - Tbilisi, Publish House "DANI"

[20] Mehta, G. S. (1996). Uttarakhand: Prospects of Development. New Delhi: Indus Publishing Company.

[21] International Fund for Agricultural Development (IFAD, 2014), Georgia Rural Development Programme for Mountainous and Highland Areas, Report No. 3254-GE.

[22] Guoping Huang (2017), "Modeling Urban Spatial Growth in Mountainous Regions of Western China", Mountain Research and Development, 37(3), pp.367-376.https://doi.org/10.1659/MRD-JOURNAL-D-1600078.1. 